\section{War Is Over. Give Peace a Chance (with apologies to the late John Lennon)}

\section{To the Editor:}

In his recent essay on fibromyalgia syndrome (FMS), entitled "Fibromyalgia Wars," Wolfe ${ }^{1}$ paints a picture of this condition as one that epitomizes a conflict between practicing physicians, on the one hand, and an assortment of organized, powerful antagonists including academics, the pharmaceutical industry, patient support groups, lawyers, the Food and Drug Administration, the World Health Organisation, and the American College of Rheumatology. Casting oneself as the underdog is a good ploy for attracting sympathy and more easily enables the use of emotive rather than rational arguments. A "straw man" is erected and then attacked primarily using speculative concepts and ideas derived from a few medical historians.

In contrast to the controlling influence of a "pharmaco-academic complex" (p. 672) in FMS portrayed by Wolfe, our personal experience has been that an interest in FMS has typically been regarded by our academic colleagues with politely disguised condescension, if not outright pity. Support groups, at least in Canada, have been politically ineffective, and the pharmaceutical industry was, until quite recently, conspicuous by its absence. The pendulum may have swung somewhat in the past 3 or 4 years, but certainly not as widely as Wolfe would have it. lows:

As far as we can discern, Wolfe's arguments against FMS are as fol-

1. FMS is part of a continuum of pain and other distress and therefore should not be considered a separate entity;

2. The absence of "a specific pathological process";

3. The socially and emotionally deleterious effects of labeling;

4. FMS is a "socially constructed illness";

5. The lack of progress in improving the symptoms of FMS.

We will briefly address each of these points:

FMS is part of a continuum of pain and other distress and therefore should not be considered a separate entity. FM may well be part of a continuum of pain and distress labeled by some epidemiologists as "chronic widespread pain" (CWP). Many well accepted medical conditions fall along continua (e.g., hypertension, diabetes, obesity, and osteoporosis). Not all medical illness is dichotomous. In a continuum, normal becomes abnormal because a group of experts, using a statistical cutoff point and/or a consensus of opinion, has drawn a line in the sand. Moreover, artificial dichotomies are sometimes adopted. Why, for instance, must a patient meet 4 rather than 3 of the criteria for systemic lupus erythematosus (SLE) before being so labeled? It is unclear to us why being a continuum-based entity should serve as a rejection criterion for FMS but not other medical illnesses. We feel that the acceptability of FMS as a diagnostic entity should be based at least partly on its heuristic value. As efficacious treatments for FMS have been developed, the heuristic value of the diagnosis has only increased. We have shown, incidentally, that there are clinically, socially, and statistically significant differences between patients with CWP who meet the diagnostic criteria for FMS (those with $\geq 11$ tender points) and those who have fewer than 11 tender points ${ }^{2}$.

The absence of "a specific pathological process." Are pathological processes really absent in FMS? What about abnormalities in functional magnetic resonance imaging, high levels of substance $\mathrm{P}$ in the cerebrospinal fluid, low levels of human growth hormone, abnormalities in the hypothalamic pituitary axis, abnormal norepinephrine blood levels at rest and on stimulation, and abnormal nociceptive flexion reflex responses ${ }^{3-8}$ ? Not specific? Perhaps, but are rheumatoid factor and antinuclear antibody specific? At this point in our understanding of FMS it seems no longer correct to suggest that pathological processes are absent.

The socially and emotionally deleterious effects of labeling. Contrary to speculative claims of harm made cited by Wolfe (p. 676), the scientific evidence actually suggests the opposite: individuals are not made worse when a diagnostic label is applied ${ }^{9}$ and society may be much better off, if for no other reason than decreased medical expenditures ${ }^{10}$.
FMS is a "socially constructed illness." The argument of "socially constructed illness" is a potent weapon. One can always use it, even if the scientific facts argue otherwise. Like Freud's psychoanalytic theory, also once popular despite lack of scientific evidence and testability, it cannot be proven or disproven. One example cited by Wolfe is Ivan Illich's work on the medicalization of illness (p. 573). Illich popularized the concept of iatrogenic illness (e.g., drug-induced illness, postoperative side effects) and medicalization of normal life experiences (birth, death) where medical intervention can do more harm than good. As we have noted above, that is clearly not the case with FMS.

Another viewpoint is that, throughout the history of medicine, illnesses have often been attributed to social and psychological rather than biological causes. Poorly understood diseases have been attributed to the psyche when the pathophysiology was not understood. Indeed, some of us still remember how peptic ulcer was a classical psychosomatic condition (today it might have been classified by some as a Medically Unexplained Symptom). What a pity that $H$. pylori put an end to this cherished concept. At one time rheumatoid arthritis, inflammatory bowel disease, asthma, hypertension, and hyperthyroidism were all considered psychosomatic illnesses ${ }^{11}$

The lack of progress in improving the symptoms of FMS. There was a time within living memory when SLE was a sentence of death, and rheumatoid arthritis a largely untreatable condition. Fortunately, we did not consider giving up on them. Some promising treatments for FM are emerging. Like many other medical treatments, they are far from perfect and will occasionally be misapplied. This suggests that physicians should be well informed and vigilant. We do not think that FM should become the disease that "dares not speak its name."

Unlike Wolfe, we do not view - nor do we wish to view - scientific discourse on FM as a war, declared or otherwise. The debate surrounding FMS has usually been spirited, sometimes heated. We hope it will not degenerate into a war. In that case, as we know only too well, the first casualty would be the truth.

We also feel that it is time to address an increasing concern. In contrast with the diagnostic label "fibromyalgia," referring to it as a "socially constructed illness" implies that there is no physiological basis and, to many, that it is ipso facto psychological or factitious. As is the case for other chronic pain problems and those diagnosed with mental illnesses, individuals with FMS are often the target of disparagement and derision. In our community, some family physicians will not take those who have FMS or other chronic pain conditions as patients. Despite the apparent benefits of diagnosis and the availability of treatments, many rheumatologists refuse to accept referrals of patients who are likely to have FMS. The "delegitimization" and "betrayal" that Wolfe notes (p. 671), often felt by patients as they interact with the medical system, isn't imagined. Would we tell a patient with systemic sclerosis (SSc) as Wolfe suggests (p. 676) for patients with FMS: "Some doctors call your problems scleroderma. Scleroderma is the name we give to such problems, not the cause of the problems"? We are not any closer to identifying the "cause" of SSc than that of FMS. Prejudice and discrimination do not have a place in medical care, yet with FMS and chronic pain conditions more generally, they are now "the elephant in the room" in many discussions of FMS. Wolfe quotes The New York Times; perhaps we can take the liberty of citing Time magazine: "I know all too well how most doctors really feel about people with chronic pain who don't get better: disdainful and contemptuous... There is a real sense of the patient as a failure and a weak person who can't pull him- or herself together and cope." Michigan physician with severe neck pain from a 1999 auto accident (quoted in Time, Feb. 28, 2005) 2 .

We agree with Yunus ${ }^{13}$ that the use of anachronistic terms such as "medically unexplained symptoms," "somatization," "somatization disorder," and "functional somatic syndromes" derived from Cartesian organic/non-organic models of illness should be abandoned. Indeed, it has been recommended that the diagnosis of Pain Disorder be deleted from the next version of the Diagnostic and Statistical Manual of Mental Disorders Version 5 (DSM-V) such that pain symptoms would always be coded as a Personal non-commercial use only. The Journal of Rheumatology Copyright (c) 2009. All rights reserved. 
medical condition (Axis III) and any concomitant psychiatric comorbidity on Axis $\mathrm{I}^{14}$. In addition to the lack of scientific support for the diagnosis, it was recognized that assigning patients with pain problems to Axis I had been stigmatizing.

Is it not time to stop engaging in a "battle for symptom legitimacy," and to use the tools we have available to improve the health and quality of life of patients with FMS?

MANFRED HARTH, MD, University of Western Ontario, Medicine (Rheumatology); WARREN NIELSON, PhD, St. Joseph's Health Care, Rheumatology Day Programs, London, Ontario, Canada. Address correspondence to Dr. Nielson, warren.nielson@sjhc.london.on.ca or Dr. Harth, harth@aimhealthgroup.com

\section{ACKNOWLEDGMENT}

We thank Marilyn L. Hill for her helpful comments.

\section{REFERENCES}

1. Wolfe F. Fibromyalgia wars. J Rheumatol 2009;36:671-8.

2. White KP, Speechley M, Harth M, Ostbye T. The London Fibromyalgia Epidemiology Study: comparing the demographic and clinical characteristics in 100 random community cases of fibromyalgia versus controls. J Rheumatol 1999;26:1577-85.

3. Gracely RH, Petzke F, Wolf JM, Clauw DJ. Functional magnetic resonance imaging evidence of augmented pain processing in fibromyalgia. Arthritis Rheum 2002;46:1333-43.

4. Russell IJ, Orr MD, Littman B, Vipraio GA, Alboukrek D, Michalek JE, et al. Elevated cerebrospinal fluid levels of substance $\mathrm{P}$ in patients with the fibromyalgia syndrome. Arthritis Rheum 1994;37:1593-601.

5. Russell IJ, Orr MD, Littman B, Vipraio GA, Alboukrek D, Michalek JE, et al.The growth hormone (GH)-releasing hormone-GH-insulin-like growth factor-1 axis in patients with fibromyalgia syndrome. J Clin Endocrinol Metab 1999;84:3378-81.

6. Crofford LJ, Young EA, Engleberg NC, Korszun A, Brucksch CB,
McClure LA, et al. Basal circadian and pulsatile ACTH and cortisol secretion in patients with fibromyalgia and/or chronic fatigue syndrome. Brain Behav Immun 2004;18:314-25.

7. Torpy DJ, Papanicolaou DA, Lotsikas AJ, Wilder RL, Chrousos GP, Pillemer SR. Responses of the sympathetic nervous system and the hypothalamic-pituitary-adrenal axis to interleukin-6: a pilot study in fibromyalgia. Arthritis Rheum 2000;43:872-80.

8. Desmeules JA, Cedraschi C, Rapiti E, Baumgartner E, Finckh A, Cohen P, et al. Neurophysiologic evidence for a central sensitization in patients with fibromyalgia. Arthritis Rheum 2003;48:1420-9.

9. White KP, Nielson WR, Harth M, Ostbye T, Speechley M. Does the label "fibromyalgia" alter health status, function, and health service utilization? A prospective, within-group comparison in a community cohort of adults with chronic widespread pain. Arthritis Rheum 2002;47:260-5.

10. Annemans L, Wessely S, Spaepen E, Caekelbergh K, Caubère JP, Le Lay $\mathrm{K}$, et al. Health economic consequences related to the diagnosis of fibromyalgia syndrome. Arthritis Rheum 2008;58:895-902.

11. Marmor J. Modern psychoanalysis: New directions and perspectives. New York: Basic Books; 1968.

12. Wallis $\mathrm{C}$. The right (and wrong) way to treat pain. Hint: it takes more than a prescription pad to bring relief. Time 2005;166:46.

13. Yunus MB. Central sensitivity syndromes: a new paradigm and group nosology for fibromyalgia and overlapping conditions, and the related issue of disease versus illness. Semin Arthritis Rheum 2008;37:339-52.

14. Kroenke K, Sharpe M, Sykes R. Revising the classification of somatoform disorders: key questions and preliminary recommendations. Psychosomatics 2007;48:277-85.

J Rheumatol 2009;36:12; doi:10.3899/jrheum.090508 